\title{
Determinan Permintaan Jasa Transportasi Penyeberangan Antar Pulau Di Pelabuhan Marampa Kabupaten Manokwari
}

\author{
Marcus R, Maspaitella ${ }^{1}$, Ketysia I. Tewernussa ${ }^{2}$ Rizza Siwalette $^{3}$ \\ ${ }^{1,2}$ Dosen Jurusan Ekonomi Pembangunan, Universitas Papua \\ ${ }^{3}$ Alumni Jurusan Ekonomi Pembangunan, Universitas Papua
}

Received: Mei 2019; Accepted: Juli 2019; Published: September 2019

\begin{abstract}
Abstrak
Penelitian ini bertujuan untuk mengetahui pengaruh harga tiket, tingkat pendapatan dan kualitas pelayanan terhadap permintaan jasa transportasi penyeberangan antar pulau di Pelabuhan Marampa Kabupaten Manokwari. Sampel penelitian ini berjumlah 75 responden penumpang. Analisis data dalam penelitian ini menggunakan analisis regresi linear berganda. Hasil penelitian menunjukkan bahwa tingkat pendapatan berpengaruh signifikan terhadap permintaan jasa transportasi penyeberangan antar pulau di Pelabuhan Marampa Manokwari, sedangkan harga tiket dan kualitas pelayanan bukan tidak memberikan pengaruh yang signifikan. Implikasi dari penelitian ini adalah bahwa substitusi moda transportasi lain dapat terjadi jika adanya kenaikan tingkat pendapatan penumpang. Selain itu, peningkatan kualitas pelayanan perlu terus dilakukan baik oleh pemerintah daerah maupun pihak pengelola pelabuhan.
\end{abstract}

Kata kunci: permintaan jasa transportasi, pelabuhan Marampa, Manokwari

\begin{abstract}
This study aims to determine the effect of ticket prices, income levels and service quality on demand for interisland crossing transportation services in Marampa Port, Manokwari Regency. The sample of this study was 75 passenger respondents. Data analysis in this study uses multiple linear regression analysis. The results showed that the level of income had a significant effect on demand for inter-island crossing transportation services at Marampa Port in Manokwari, while ticket prices and service quality did not have a significant effect. The implication of this research is that the substitution of other modes of transportation can occur if there is an increase in the level of passenger income. In addition, improving the quality of services needs to be continued both by the local government and the port administrator.
\end{abstract}

Keywords: demand on transportation service, Marampa seaport, Manokwari

How to Cite: Maspaitella, M. R., Tewernussa, K. I., Siwalette, R. (2019). Determinan Permintaan Jasa Transportasi Penyeberangan Antar Pulau Di Pelabuhan Marampa Kabupaten Manokwari. JFRES: Journal of Fiscal and Regional Economy Studies, 2 (2), 60 - 66.

\footnotetext{
Corresponding author :

E-mail: max_maspaitella@yahoo.co.id
} 


\section{PENDAHULUAN}

Salah satu sektor usaha yang cukup penting dalam mendukung perekonomian suatu daerah adalah sektor transportasi laut, karena tidak dapat dipungkiri bahwa sarana transportasi laut di negara kepulauan seperti Indonesia telah menjadi tulang punggung utama pergerakan distribusi barang dalam skala besar dengan menggunakan kapal laut, sehingga dari segi ekonomi dan bisnis penggunaan sarana transportasi dengan kapal laut lebih efektif dan besar manfaatnya. Dengan adanya sarana prasarana transportasi laut untuk pemindahan barang dari suatu tempat ke tempat lainnya, diharapkan akan dapat diikuti oleh aktivitas ekonomi masyarakat yang berdampak positif dalam peningkatan ekonomi suatu wilayah.

Papua Barat sebagai salah satu wilayah di Indonesia bagian timur, yang memiliki posisi geografis sangat strategis dibagian barat Pulau Papua. Posisi ini membuat Papua Barat sebagai pintu masuk pada persilangan jalur transportasi dan perdagangan baik untuk wilayah bagian utara maupun bagian selatan wilayah Pulau Papua. Berbagai kapal dari wilayah bagian barat, tengah, maupun wilayah timur di Indonesia menjadikan pelabuhan laut dan pelabuhan udara Papua Barat sebagai jalur transit. Oleh karena itu tidak dapat dipungkiri bahwa sektor perhubungan di Papua Barat memiliki peranan yang sangat dominan baik bagi perkembangan ekonomi regional, nasional atau bahkan internasional.

Kunjungan kapal di pelabuhan merupakan salah satu indikator yang dapat menggambarkan tingkat kesibukan aktivitas suatu pelabuhan. Dimana jumlah kunjungan kapal pada pelabuhan yang diusahakan di Papua Barat menurut jenis pelayaran pada tahun 2015 hingga tahun 2017 mengalami peningkatan. Dibandingkan dengan tahun sebelumnya, pada tahun 2017 total frekuensi kunjungan kapal mengalami peningkatan sebesar 1299 kunjungan. Jika dilihat berdasarkan jenis pelayaran, pada tahun 2017 frekuensi kunjungan dari pelayaran dalam negeri mengalami peningkatan sebesar 622 kunjungan dari tahun sebelumnya. Pelayaran luar negeri mengalami peningkatan frekuensi kunjungan yang sangat signifikan sebesar 677 kunjungan lebih banyak dari tahun sebelumnya (BPS, 2017).

Berdasarkan Tabel 1, frekuensi kunjungan kapal paling banyak terdapat di pelabuhan Kota Sorong baik pelayaran dalam negeri maupun pelayaran luar negeri. Pelabuhan Kota Sorong merupakan salah satu pelabuhan paling ramai di wilayah Provinsi Papua Barat. Tercatat pada tahun 2017 di pelabuhan Kota Sorong terdapat 946 kunjungan kapal untuk pelayaran dalam negeri, dimana terjadi peningkatan frekuensi kunjungan kapal sebesar 359 kunjungan kapal lebih banyak dibandingkan tahun 2016. Sementara pelayaran luar negeri pada tahun 2017 tercatat mengalami peningkatan frekuensi kunjungan kapal di pelabuhan Kota Sorong sebesar 678 kunjungan kapal lebih banyak dibanding tahun 2016.

Pelabuhan laut Kabupaten Manokwari menjadi salah satu pintu masuk Provinsi Papua Barat dan sebagai penyangga bagi kabupaten lain. Tentunya pelabuhan laut Kabupaten Manokwari memegang peran penting bagi perkembangan ekonomi dan perencanaan pembangunan Provinsi Papua Barat secara umum. Pelabuhan laut Kabupaten Manokwari yang diusahakan adalah pelabuhan laut yang dikelola oleh PT. (Persero) Pelabuhan Indonesia IV yang memberikan fasilitasfasilitas yang diperlukan bagi kapal yang memasuki pelabuhan untuk bongkar muat barang dan lain-lain.

Tabel 1. Kunjungan Kapal di Provinsi Papua Barat 2015-2017 (Unit)

\begin{tabular}{ccccccc}
\hline Pelabuhan & \multicolumn{2}{c}{ Pelayaran Dalam Negeri } & \multicolumn{3}{c}{ Pelayaran Luar Negeri } \\
\cline { 2 - 7 } & $\mathbf{2 0 1 5}$ & $\mathbf{2 0 1 6}$ & $\mathbf{2 0 1 7}$ & $\mathbf{2 0 1 5}$ & $\mathbf{2 0 1 6}$ & $\mathbf{2 0 1 7}$ \\
\hline Fakfak & 408 & 352 & 408 & 0 & 0 & 0 \\
Manokwari & 861 & 716 & 923 & 5 & 5 & 4 \\
Kota Sorong & 1,068 & 716 & 946 & 29 & 22 & 700 \\
\hline Jumlah & $\mathbf{2 , 3 3 7}$ & $\mathbf{1 , 6 5 5}$ & $\mathbf{2 2 7 7}$ & $\mathbf{3 4}$ & $\mathbf{2 7}$ & $\mathbf{7 0 4}$ \\
\hline
\end{tabular}

Sumber : BPS, 2017 
Kunjungan kapal pelabuhan Manokwari mengalami penurunan pada tahun 2015-2016. Pelayaran dalam negeri tahun 2016 jumlah kunjungan kapal sebanyak 716 kunjungan kapal dimana sebelumnya pada tahun 2015 jumlah kunjungan kapal sebanyak 861. Kunjungan kapal pada pelayaran luar negeri tahun 2016-2017 stabil yaitu sebanyak 5 jumlah kunjungan kapal (BPS, 2016).

Selain pelabuhan utama Manokwari, terdapat juga pelabuhan penyeberangan antar pulau yaitu Pelabuhan Marampa yang terletak di jalan Trikora Sowi 3 Marampa. Pelabuhan Marampa merupakan salah satu pelabuhan yang menjadi jalur tranportasi masyarakat di wilayah Provinsi Papua Barat dan Papua.

Pelabuhan Marampa merupakan salah satu jalur transportasi laut yang menghubungkan kabupaten Teluk Wondama, Numfor, Serui hingga ke Kabupaten Nabire dan Kabupaten Biak. Terdapat 2 unit kapal yang beroperasi di Pelabuhan Marampa, yaitu KM Kasuari Pasifik IV dan KM Napan Wainami. KM Kasuari Pasifik IV beroperasi dari pelabuhan Marampa Manokwari menuju pulau Numfor dan juga Biak, sedangkan KM Napan Wainami beroperasi dari pelabuhan Marampa Manokwari menuju Biak, Serui, Waren dan juga Nabire. Kapal-kapal tersebut terbilang kecil dan muatan penumpang tidak mencapai ribuan seperti kapal besar. Muatan penumpang hanya berkisar 100 hingga 300 jiwa belum ditambah kendaraan, dan barang-barang yang dibawa penumpang seperti buah-buahan serta sayur-sayuran.

Penelitian ini bertujuan untuk mengetahui pengaruh harga tiket, pendapatan, dan kualitas pelayanan terhadap permintaan jasa transportasi penyeberangan antar pulau di Pelabuhan Marampa Kabupaten Manokwari.

\section{METODE PENELITIAN}

\section{Populasi dan Sampel}

Populasi penelitian ini adalah penumpang jasa transportasi penyeberangan antar pulau di Pelabuhan Marampa Manokwari, yang merupakan pengguna jasa transportasi penyeberangan antar pulau. Penarikan sampel dalam penelitian ini menggunakan Non Probability Sampling dengan teknik sampling aksidental. Dalam teknik sampling aksidental, pengambilan sampel tidak ditetapkan lebih dahulu. Peneliti langsung saja mengumpulkan data dari unit sampling yang ditemui (Sugiono, 2001). Jumlah sampel dalam penelitian adalah sebanyak 75 responden. Jumlah tersebut dianggap telah memenuhi kejenuhan sampel dan diharapkan telah mewakili populasi yang sifatnya tidak diketahui secara akurat.

\section{Data}

Data yang digunakan dalam penelitian ini adalah terdiri dari data primer dan data sekunder. Data primer diperoleh dari lapangan melalui wawancara langsung dengan responden. Sedangkan data sekunder berupa publikasi resmi seperti laporan dari perusahaan Angkutan Sungai Danau dan Penyeberangan (ASDP), laporan makalah-makalah, jurnaljurnal, dan kepustakaan lainnya. Metode analisis data adalah model ekonometrika dengan menggunakan perhitungan secara regresi linier berganda yaitu :

$\begin{array}{ll}\mathrm{Y}=\alpha+\beta_{1} \mathrm{X}_{1}+\beta_{2} \mathrm{X}_{2}+\beta_{3} \mathrm{X}_{3}+\mathrm{e} \\ \text { Dimana : } & \\ \mathrm{Y} & : \text { Permintaan jasa transportasi } \\ \alpha & : \text { Konstanta } \\ \beta_{1}, \beta_{2}, \beta_{3} & : \text { Koefisien regresi } \\ \mathrm{X}_{1} & \text { : Harga tiket } \\ \mathrm{X}_{2} & \text { : Pendapatan } \\ \mathrm{X}_{3} & \text { : Kualitas pelayanan } \\ \mathrm{e} & \text { :Standart error }\end{array}$

\section{Operasionalisasi dan Pengukuran Variabel}

\section{Harga Tiket}

Harga tiket dalam penelitian ini adalah persepsi keterjangkauan konsumen atas kebijakan yang ditetapkan oleh pihak perusahaan guna mendapatkan sejumlah kombinasi dari jasa pelayanan yang diberikan. Adapun indikator-indikator harga tiket dalam penelitian ini antara lain: Harga tiket relatif murah, kenaikan harga tiket, kesesuaian harga dengan fasilitas yang diterima, dan kesesuaian harga dengan pelayanan. Setiap indikator harga tiket diukur dengan menggunakan skala Likert, dengan skor 1 (terendah) untuk pernyataan sangat tidak setuju, dan skor 5 (tertinggi) untuk pernyataan sangat setuju.

\section{Pendapatan}

Pendapatan merupakan jumlah semua upah atau gaji yang diterima responden, dan diukur dalam satuan rupiah per bulan. 


\section{Kualitas Pelayanan}

Kualitas pelayanan merupakan tingkatan kondisi baik buruknya suatu pelayanan dapat dinilai melalui kualitas pelayanan yang diberikan oleh penyelenggara pelayanan. Adapun indikator-indikator kualitas pelayanan dalam penelitian ini yaitu: pelayanan sesuai harapan penumpang, keramahan petugas dalam melayani penumpang, kepuasan layanan yang diterima penumpang, ketersediaan makanan dan minuman, dan layanan temapat tidur dan tempat duduk. Setiap indikator kualitas pelayanan akan diukur dengan menggunakan skala Likert, dengan skor 1 (terendah) untuk pernyataan sangat tidak setuju, dan skor 5 (tertinggi) untuk pernyataan sangat setuju.

\section{Permintaan Jasa Transportasi}

Permintaan jasa transportasi adalah intensitas penggunan jasa transportasi yang diukur dari seberapa seringnya (berapa kali) responden melakukan perjalanan dari Manokwari ke Biak maupun Manokwari ke Numfor dengan memakai jasa transportasi penyeberangan selama setahun.

\section{HASIL DAN PEMBAHASAN}

\section{Analisis Deskriptif Responden}

Tabel 2. Karakteristik Responden

\begin{tabular}{llcc}
\hline \multicolumn{1}{c}{ Karakteristik Responden } & Jumlah (Jiwa) & Nisbah (\%) \\
\hline Jenis kelamin : & Laki-laki & 42 & \\
& Perempuan & 33 & 56,00 \\
Umur : & & & 44,00 \\
& 20 tahun & 9 & 12,00 \\
& 20-50 tahun & 64 & 85,33 \\
Pekerjaan : & $<50$ tahun & 2 & 2,67 \\
& Pelajar/mahasiswa & 39 & 52,00 \\
& PNS & 3 & 4,00 \\
& Swasta & 17 & 22,67 \\
& Wiraswasta & 3 & 4,00 \\
& Petani & 2 & 2,67 \\
& Ibu Rumah Tangga & 4 & 5,33 \\
& Lainnya & 7 & 9,33 \\
Tingkat Pendidikan : & & 1 & 1,33 \\
& SD & 3 & 4,00 \\
& SMP & 48 & 64,00 \\
& SMA & 23 & 30,67 \\
D3/S1 & & 26,67 \\
Status Perkawinan : & Kawin & 20 & 73,33 \\
\hline & Belum Kawin & 55 &
\end{tabular}

Gambaran tentang responden diklasifikasikan berdasarkan jenis kelamin, umur, pekerjaan, pendidikan terakhir, dan status perkawinan

Berdasarkan jenis kelamin, terdapat $56 \%$ responden laki-laki dan $44 \%$ responden perempuan. Rata-rata umur responden adalah antara 20-50 tahun (85,33\%), dan masih tergolong usia kerja. Berdasarkan pekerjaan, lebih dari setengah responden penelitian ini adalah pelajar dan mahasiswa (52\%), diikuti oleh pekerja swasta $(22,67 \%)$. Jika dilihat dari tingkat pendidikan, maka mayoritas responden telah menyelesaikan tingkat pendidikan SMA dan perguruan tinggi. Berdasarkan status perkawinan, sebanyak $73,33 \%$ responden tergolong dalam kategori belum kawin.

\section{Deskripsi Variabel}

\section{Harga Tiket (XI)}

Harga tiket dinilai berdasarkan persepsi responden terhadap empat aspek harga, yaitu: Harga tiket relatif murah, kenaikan harga tiket, kesesuaian harga dengan fasilitas yang diterima, dan kesesuaian harga dengan pelayanan. Tabel 3 menyajikan hasil skoring penilaian terhadap harga tiket. (Tabel 2).

\section{Sumber : Data Primer Diolah, 2019}


Tabel 3. Persepsi Responden terhadap Harga Tiket

\begin{tabular}{cccc}
\hline No & Skor & Jumlah (jiwa) & Nisbah (\%) \\
\hline 1 & $4-7$ & 2 & 3 \\
2 & $8-13$ & 11 & 15 \\
3 & $14-17$ & 35 & 46 \\
4 & $18-20$ & 27 & 36 \\
\hline \multicolumn{2}{l}{ Total } & $\mathbf{7 5}$ & $\mathbf{1 0 0}$ \\
\hline
\end{tabular}

\section{Sumber : Data Primer Diolah, 2019}

Berdasarkan Tabel 3, sebanyak 46\% responden memiliki persepsi baik terhadap harga tiket, $36 \%$ responden mempunyai persepsi sangat baik terhadap harga tiket. Terdapat hanya sekitar 3\% responden yang memberikan persepsi kurang baik terhadap harga tiket. Hal ini memberikan gambaran bahwa secara umum, harga tiket yang diberlakukan pada jasa angkutan penyeberangan di Pelabuhan Marampa telah sesuai dengan penyediaan fasilitas dan pelayanan yang diterima penumpang.

\section{Pendapatan Responden (X2)}

Karakteristik responden yang menggunakan jasa transportasi penyeberangan antar pulau di pelabuhan Marampa Kabupaten Manokwari berdasarkan pendapatan perbulan dapat dilihat pada Tabel 4.

Berdasarkan Tabel 4, sebanyak 48\% responden memiliki pendapatan per bulan antara $\mathrm{Rp}$ $500.000-1.000 .000,17 \%$ responden memiliki pendapatan antara Rp. 1.000.000 - 2.000.000, dan diikuti oleh $15 \%$ responden memiliki pendapatan antara Rp. $2.000 .000-3.000 .000$. Hal ini dikarenakan jumlah responden yang paling banyak menggunakan jasa transportasi penyeberangan antar pulau adalah responden dengan golongan ekonomi menengah ke bawah yang meliputi pelajar/mahasiswa dan kelompok ibu rumah tangga.

Tabel 4. Sebaran Responden Berdasarkan Pendapatan per Bulan

\begin{tabular}{cccc}
\hline No & Pendapatan (Rp) & Jumlah (jiwa) & Nisbah (\%) \\
\hline 1 & $<500.000$ & 6 & 8 \\
2 & $500.000-1.000 .000$ & 36 & 48 \\
3 & $1.100 .000-2.000 .000$ & 13 & 17 \\
4 & $2.100 .000-3.000 .000$ & 11 & 15 \\
5 & $3.100 .000-4.000 .000$ & 4 & 5 \\
6 & $>4.000 .000$ & 5 & 7 \\
\hline
\end{tabular}

\section{Sumber : Data Primer Diolah, 2019}

\section{Kualitas Pelayanan (X3)}

Karakteristik responden berdasarkan pengelompokan kriteria dan skor pernyataan pada variabel kualitas pelayanan terhadap permintaan jasa transportasi disajikan pada Tabel 5.

Sebanyak $44 \%$ responden memiliki persepsi cukup baik terhadap kualitas pelayanan yang diterima penumpang, dikuti $27 \%$ responden yang berpersepsi baik. Sedangkan terdapat $6 \%$ responden yang bahwa kualitas layanan jasa transportasi penyeberangan di Pelabuhan Marampa masih kurang baik. Hal ini mengindikasikan bahwa pelayanan yang diberikan kepada penumpang belum terlalu memadai, dan perlu ditingkatkan lagi, terutama dalam hal layanan makanan dan minuman, serta penyediaan tempat tidur dan kursi kepada penumpang.

Tabel 5. Persepsi Responden terhadap Kualitas Pelayanan

\begin{tabular}{cccc}
\hline No & Skor & Jumlah (jiwa) & Nisbah (\%) \\
\hline 1 & $5-9$ & 6 & 8 \\
2 & $10-14$ & 13 & 17 \\
3 & $15-18$ & 33 & 44 \\
4 & $19-22$ & 20 & 27 \\
5 & $23-25$ & 3 & 4 \\
\hline & Total & $\mathbf{7 5}$ & $\mathbf{1 0 0}$ \\
\hline
\end{tabular}

Sumber : Data Primer Diolah, 2019 


\section{Permintaan Jasa Transportasi (Y)}

Permintaan jasa transportasi penyeberangan antar pulau dalam penelitian ini adalah intensitas/frekuensi penumpang bepergian dengan menggunakan kapal di Pelabuhan Marampa. Data jumlah permintaan jasa transportasi ini disajikan pada Tabel 6 .
Berdasarkan data Tabel 6, lebih dari setengah (56 \%) responden mempunyai frekuensi bepergian 4-6 kali per tahun, diikuti oleh $37,33 \%$ responden yang mempunyai frekuensi bepergian 1-3 kali per tahun. Hanya sekitar $6,67 \%$ responden yang mempunyai frekuensi bepergian lebih dari 6 kali dalam setahun.

Tabel 6. Sebaran Responden Berdasarkan Frekuensi Permintaan Jasa Transportasi

\begin{tabular}{cccc}
\hline No & Intensitas Permintaan & Jumlah (jiwa) & Nisbah (\%) \\
\hline 1 & 1-3 kali pertahun & 28 & 37,33 \\
2 & 4-6 kali per tahun & 42 & 56,00 \\
3 & $>6$ kali per tahun & 5 & 6,67 \\
\hline & Total & $\mathbf{7 5}$ & $\mathbf{1 0 0}$ \\
\hline
\end{tabular}

Sumber: Data Primer Diolah, 2019

\section{Model Regresi Linear Berganda}

Nilai koefisien determinasi $\left(\mathrm{R}^{2}\right)$ sebesar 0,108 (Tabel 7) mengindikasikan bahwa variasi dalam permintaan jasa transportasi penyeberangan antar pulau dijelaskan oleh hanya $10,8 \%$ variasi variabel-variabel bebasnya. Sedangkan masih terdapat 89,2\% variasi permintaan yang ditentukan oleh variabel lainnya yang tidak termasuk dalam model ini.

Selanjutnya hasil regresi linear berganda (Tabel 8) adalah sebagai berikut:

$\mathrm{Y}=2.562+0.060 \mathrm{X}_{1}-0.093 \mathrm{X}_{2}+0.111 \mathrm{X}_{3}+\mathrm{e}$

Koefisien regresi variabel harga tiket adalah sebesar 0.060, dengan nilai signifikansi 0,766. Ini berarti bahwa pengaruh harga tiket terhadap permintaan jasa transportasi penyeberangan antar pulau di pelabuhan Marampa adalah positif, tetapi tidak signifikan. Hasil ini kontradiktif dengan penelitian yang dilakukan oleh Darmanto (2014) yang menyatakan bahwa harga tiket adalah variabel yang berpengaruh signifikan terhadap permintaan jasa transportasi.

Tabel 7. Koefisien Determinasi

\begin{tabular}{ccccc}
\hline \multicolumn{5}{c}{ Model Summary } \\
\hline Model & R & R Square & Adjusted R Square & Std. Error of the Estimate \\
\hline 1 & $.328^{\text {a }}$ & .108 & .070 & .209 \\
\hline
\end{tabular}

Tabel 8. Hasil Uji Statistik

\begin{tabular}{|c|c|c|c|c|c|c|}
\hline \multicolumn{7}{|c|}{ Coefficients $^{\mathrm{a}}$} \\
\hline & \multirow[t]{2}{*}{ Model } & \multicolumn{2}{|c|}{ Unstandardized Coefficients } & \multirow{2}{*}{$\begin{array}{c}\begin{array}{c}\text { Standardized } \\
\text { Coefficients }\end{array} \\
\text { Beta } \\
\end{array}$} & \multirow[t]{2}{*}{$\mathbf{t}$} & \multirow[t]{2}{*}{ Sig. } \\
\hline & & B & Std. Error & & & \\
\hline \multirow[t]{4}{*}{1} & (Constant) & 2.562 & 2.021 & & 1.267 & .209 \\
\hline & $\mathrm{X} 1$ & .060 & .201 & .043 & .298 & .766 \\
\hline & $\mathrm{X} 2$ & -.093 & -3.382 & -.382 & -2.561 & .013 \\
\hline & $\mathrm{X} 3$ & .111 & .084 & .163 & 1.321 & .191 \\
\hline
\end{tabular}

Journal of Fiscal and Regional Economy Studies

Koefisien regresi untuk variabel kualitas pelayanan sebesar $0.111 \quad($ sig. $=0.191)$ menunjukkan bahwa kualitas pelayanan berpengaruh positif terhadap permintaan jasa transportasi penyeberangan antar pulau di pelabuhan Marampa Kabupaten Manokwari namun tidak signifikan. Hasil ini tidak sejalan dengan penelitian Darmanto (2014) yang menyatakan kualitas pelayanan berpengaruh positif dan berpengaruh signifikan terhadap permintaan jasa transportasi angkutan laut.

Koefisien regresi variabel pendapatan sebesar Hal ini mengindikasikan bahwa variabel pendapatan memiliki pengaruh yang signifikan penyeberangan antar pulau yang disediakan di pelabuhan Marampa Kabupaten Manokwari. Semakin besar pendapatan penumpang, maka terhadap jasa transportasi penyeberangan antar pulau di pelabuhan Marampa. Hasil penelitian pendapatan adalah negatif dan signifikan terhadap permintaan jasa transportasi laut. 
Secara keseluruhan, implikasi dari hasil penelitian ini antara lain:

1. Permintaan jasa transportasi penyeberangan di pelabuhan Marampa Kabupaten Manokwari tidak terlalu dipengaruhi oleh harga tiket, tetapi berkaitan erat dengan kebutuhan penumpang. Keperluankeperluan seperti kunjungan keluarga dan kunjungan yang berkaitan dengan urusan bisnis masih merupakan pertimbangan utama penumpang dibandingkan dengan harga tiket yang berlaku saat ini.

2. Faktor tingkat pendapatan merupakan faktor yang penting dalam permintaan jasa angkutan penyeberangan di Pelabuhan Marampa Kabupaten Manokwari. Hasil penelitian menunjukkan bahwa ada hubungan terbalik antara kedua variabel ini. Hal ini mengindikasikan bahwa, dalam kondisi ceteris paribus, maka ada kecenderungan penumpang untuk melakukan substitusi moda angkutan lain pada saat terjadi peningkatan pendapatan.

3. Tingkat permintaan jasa transportasi penyeberangan di pelabuhan Marampa juga tidak dipengaruhi oleh kualitas layanan yang diterima oleh penumpang. Hasil penelitian ini menunjukkan bahwa mayoritas penumpang adalah masyarakat golongan ekonomi bawah dan menengah, sehingga aspek-aspek yang berkaitan dengan kualitas pelayanan tidak menjadi faktor penting dalam permintaan jasa angkutan di pelabuhan Marampa. Walaupun demikian, dari hasil analisis deskriptif, kualitas layanan dipersepsikan belum terlalu baik, sehingga peningkatan kualitas layanan, baik dari sisi fasilitas maupun pelayanan perlu dilakukan di waktu-waktu yang akan datang.

\section{KESIMPULAN DAN SARAN}

Berdasarkan hasil penelitian ini, maka terdapat beberapa kesimpulan sebagai berikut :
1. Harga tiket tidak berpengaruh signifikan terhadap permintaan jasa transportasi penyeberangan antar pulau di Pelabuhan Marampa Kabupaten Manokwari.

2. Pendapatan berpengaruh signifikan terhadap permintaan jasa transportasi penyeberangan antar pulau di Pelabuhan Marampa Kabupaten Manokwari.

3. Harga tiket dan kualitas pelayanan tidak berpengaruh signifikan terhadap permintaan jasa transportasi penyeberangan antar pulau di Pelabuhan Marampa Kabupaten Manokwari.

Rekomendasi dari hasil penelitian adalah bahwa pihak pengelola, baik PT. ASDP Indonesia Ferry (Persero) dan UPT Pelabuhan Marampa, terus malakukan upaya-upaya untuk meningkatkan kualitas pelayanan dan terus meningkatkan inovasi dalam hal pelayanan bagi penumpang di dalam pelayaran penyeberangan antar pulau.

\section{DAFTAR PUSTAKA}

Badan Pusat Statistik 2016, Kabupaten Manokwari Dalam Angka, Statistik Transportasi Kabupaten Manokwari.

Badan Pusat Statistik 2017, Statistik Transportasi Provinsi Papua Barat

Darmanto, A. 2014. Faktor Yang Mempengaruhi Permintaan Jasa Transportasi Penyeberangan Antar Pulau di Kota Raha. Sulawesi Tenggara: Skripsi. Universitas Hasanuddin, Makassar.

Sugiyono. 2006. Metode Penelitian Kuantitaif, Kualitatif dan $R \quad \& \quad D$ Bandung: Alfabeta.

Sukirno, S. 2009. Mikro Ekonomi:Teori Pengantar. Edisi Ketiga. Jakarta: Raja Grafindo Persada. 